\title{
Thermochemical Stability of Hybrid Halide Perovskites
}

\author{
Alessandro Senocrate, ${ }^{*},{ }^{\dagger}+\odot$ Gee Yeong Kim, ${ }^{\dagger}$ Michael Grätzel, ${ }^{\dagger, \ddagger \subset}$ and Joachim Maier ${ }^{\dagger}$ \\ ${ }^{\dagger}$ Max Planck Institute for Solid State Research, 70569 Stuttgart, Germany \\ \#École polytechnique fédérale de Lausanne, 1015 Lausanne, Switzerland
}

Supporting Information

\begin{abstract}
This contribution discusses the chemical stability of methylammonium (MA) halide perovskites (MAPbI, $\mathrm{MAPbBr}_{3}$, and $\mathrm{MAPbCl}_{3}$ ); it considers degradation processes relevant for devices (vs $\mathrm{T}, \mathrm{O}_{2}, \mathrm{H}_{2} \mathrm{O}$, voltage, illumination) by outlining their thermodynamic constraints and linking them to experimental observations. Thermodynamic considerations indicate that degradation under $\mathrm{O}_{2}$ is highly favored, albeit in principle preventable by encapsulation. The same is true for $\mathrm{H}_{2} \mathrm{O}$ exposure. Intrinsic degradation is unavoidable in devices, and under real conditions, it can be thermodynamically favored, as is the case for photodecomposition. The Gibbs energies of the decomposition reactions show strong dependences on the A-cation (decomposition vs $\mathrm{T}$ ), on the halide (vs illumination), or on both $\left(v s \mathrm{O}_{2}, \mathrm{H}_{2} \mathrm{O}\right.$ ). The stability trends vs composition change with degradation pathway, but $\mathrm{MAPbI}_{3}$ often appears as the most unstable. These serious stability issues appear to have no master solution, though some approaches (e.g., encapsulation, exploiting lower dimensionality, and alternative contact phases) have so far shown promise.
\end{abstract}

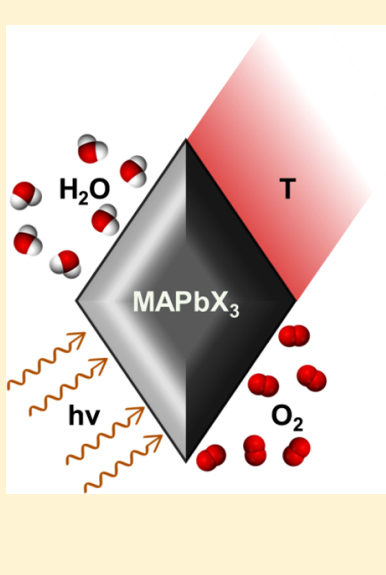

$\mathrm{H}$ ybrid halide perovskites have received a great deal of attention due to their exceptional photoelectrochemical properties and appealingly simple solution-based synthesis. These properties allow for low-temperature fabrication of high-efficiency photovoltaic devices, whereby the hybrid perovskite is used as the light-harvesting element. Notwithstanding the promising efficiencies, the presence of severe degradation phenomena in these materials poses a serious limitation to commercialization, and this is widely recognized as a major shortcoming. These decomposition processes can be induced by temperature, ${ }^{1-9}$ by high-intensity light, ${ }^{9-16}$ as well as by exposure to oxygen ${ }^{17-26}$ and/or water. $^{3,27-33}$ Despite its fundamental significance, only a handful of studies have tried to understand the underlying thermodynamics of these materials. ${ }^{7,34,35}$ Unfortunately, even these few studies are not in accordance with each other. Regarding the intrinsic stability of methylammonium lead iodide, they even lead to qualitatively different conclusions. Recent attempts have also been made to reconcile incongruous results. ${ }^{36,37} \mathrm{~A}$ clear understanding of the phase energetics (and degradation kinetics) of these materials is absolutely essential before proceeding with their study as it will reveal their suitability for practical applications.

In this contribution, we discuss the intrinsic (vs temperature) stability of methylammonium (MA)-based hybrid halide perovskites $\left(\mathrm{MAPbX}_{3}\right.$, with $\left.\mathrm{X}=\mathrm{I}, \mathrm{Br}, \mathrm{Cl}\right)$ as well as their extrinsic stabilities (vs oxygen, water, contact phases, and voltage) and stability with respect to illumination (photodegradation processes). Our discussion is largely based on thermodynamic considerations, but degradation kinetics will also be addressed. Attention will also be devoted to the thermodynamic stability of mixtures (mixed A-cation or mixed halide formulations) as these represent the state of the art materials for solar cell applications.

As the focus of our discussion is material (not device) stability and due to the lack of thermodynamic information on some of the above degradation mechanisms, we will exhaustively treat intrinsic degradation, oxygen- and voltageinduced decomposition processes, as well as mixture thermodynamics. For the purpose of completeness, other degradation processes that are due to water, contact phases, and light will not be considered in detail. Rather, we will tackle them only briefly and qualitatively and largely rely on reference to more detailed treatments in the literature.

Intrinsic Stability at Room Temperature. As already stated in the introduction, previous thermodynamic studies $, 34,35$ only partially agree on the formation enthalpies for $\mathrm{MAPbX}_{3}$ (values with respect to the elemental components are collected in the Supporting Information Table S1). As shown in Table 1, for $\mathrm{MAPbI}_{3}$, these values diverge to the point of describing a thermodynamically stable $^{7,35}$ or unstable ${ }^{34}$ material with respect to its solid halide precursors $\mathrm{PbI}_{2}$ and MAI (assuming all compounds involved to be in their standard state and at room temperature).

Received: July 26, 2019

Accepted: October 25, 2019

Published: October 25, 2019 
Table 1. Enthalpy, Entropy, and Gibbs Energy of Formation of $\mathrm{MAPbX}_{3}$ with Respect to Their Halide Precursors (MAX $\left.+\mathrm{PbX}_{2}\right)$, Calculated at $T=298 \mathrm{~K}$ and Assuming All Compounds in Their Standard State ${ }^{a}$

$\begin{array}{cccc}\text { compound } & \Delta_{\mathrm{f}} \mathrm{H}^{0} / \mathrm{kJ} \cdot \mathrm{mol}^{-1} & \Delta_{\mathrm{f}} S^{0} / \mathrm{J} \cdot \mathrm{mol}^{-1} \cdot \mathrm{K}^{-1} & \Delta_{\mathrm{f}} G^{0} / \mathrm{kJ} \cdot \mathrm{mol}^{-1} \\ \mathrm{MAPbI}_{3} & 0.5^{7} & 39.5 & -11.3 \\ & 34.5^{34} & & 22.8 \\ & 4.5^{35} & & -7.2 \\ \mathrm{MAPbBr}_{3} & -2.0^{7} & 38.6 & -13.5 \\ & 6.7^{34} & & -3.5 \\ & -6.7^{35} & & -17.0 \\ \mathrm{MAPbCl}_{3} & -2.8^{7} & 38.9 & -14.4 \\ & -9.0^{34} & & -20.6 \\ & -4.5^{35} & & -16.0\end{array}$

${ }^{a}$ Entropy values were calculated using tabulated data, in conjunction with halide perovskite values found in ref 38 .

It is important to stress that the claim of intrinsic instability contradicts various experimental observations. First, $\mathrm{MAPbI}_{3}$ can be easily synthesized mechanochemically by mixing solid $\mathrm{PbI}_{2}$ and MAI in a mortar. ${ }^{39-41}$ While this approach can introduce a certain amount of energy into the system, we observe a similar behavior under milder conditions by weakly rubbing the surfaces of $\mathrm{MAI}$ and $\mathrm{PbI}_{2}$ pellets against one another. As shown in Figure 1a, this causes an instantaneous

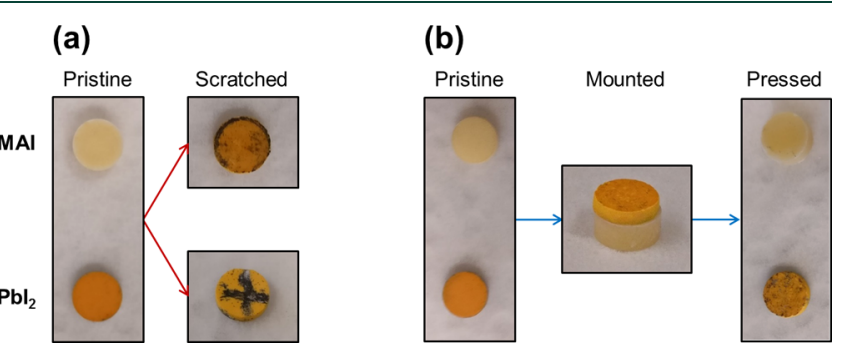

Figure 1. Phase formation experiments with MAI (white) and $\mathrm{PbI}_{2}$ (dark yellow) pellets. (a) Pellets are rubbed against one another in a circular fashion (top panel) or in an X-shape (bottom). The black phase is $\mathrm{MAPbI}_{3}$. (b) Pellets are delicately stacked and lightly spring pressed for several hours under an inert atmosphere and in the dark. After disassembling the stack, formation of the perovskite phase at the expense of the $\mathrm{PbI}_{2}$ pellet is revealed.

and significant perovskite phase formation. Second, $\mathrm{PbI}_{2}$ and MAI react in the solid state (even at room temperature) simply by allowing them to come into contact. As shown in Figure 1b, by contacting MAI and $\mathrm{PbI}_{2}$ pellets with a light spring force (carefully avoiding scratching during the assembly), formation of the black perovskite phase (at the expense of $\mathrm{PbI}_{2}$ ) is observed after several hours. In addition, by simply mixing the precursor powders (delicately rolling a bottle for a few seconds) and then letting them rest, a significant darkening of the mixture can be observed after several minutes already at room temperature. Lastly, a widely used synthetic approach to obtain $\mathrm{MAPbI}_{3}$ powders consists of dissolving the precursors in a polar aprotic solvent and subsequently removing the solvent. ${ }^{42,43}$ Even at room temperature, a substantial amount of perovskite phase can be obtained by this method. All of the above experimental evidence agree with $\mathrm{MAPbI}_{3}$ having a negative Gibbs energy of formation.

Importantly, calorimetric methods used to characterize the phase energetics of hybrid perovskites ${ }^{34,35}$ measure the heat of dissolution of the single precursors $\left(\mathrm{PbX}_{2}\right.$ and $\left.\mathrm{MAX}\right)$ and compare it with the dissolution of the final product $\left(\mathrm{MAPbX}_{3}\right)$ in the same solvent. An important assumption of such studies is that the partial molar energy of the solvated $\mathrm{Pb}$ ions is not influenced by the presence of the solvated methylammonium ions and vice versa. It is however known that for $\mathrm{PbI}_{2}$ and MAI appreciable co-dissolution effects exist. ${ }^{44}$ Such interactions can even lead to the formation of solid-state adducts, which also involve solvent molecules; these have been elucidated in the case of $\mathrm{DMSO}^{45,46}$ and DMF. ${ }^{47,48}$ The above considerations are likely to hold for other halide perovskites due to the similar chemistry, and therefore it follows that calorimetric measurements cannot be properly applied to these materials without taking into account all of the solvent-precursor and precursor-precursor interactions. We note that the above adducts would result in a calorimetric measurement that overestimates the enthalpy of formation of the perovskite phase. On the basis of these considerations, we suggest that the discrepancy between the experimental data of Nagabhushana et al. ${ }^{34}$ and that of Ivanov et al. ${ }^{35}$ may be due to the different solvents used, which are $\mathrm{HCl}$ and $\mathrm{DMSO}$, respectively. In $\mathrm{HCl}$, complications may also be given by residual solvent from the synthesis (of $\mathrm{MAPbX}_{3}$ or MAX) reacting with the acid or even by degradation of the MAX compounds in acidic environments. Indeed, when dissolving MAI in concentrated $\mathrm{HCl}$ (or any other acid), one observes a significant, light-dependent darkening of the solution over a couple hours (see the Supporting Information) due to the oxidation of iodide, which involves the acidic environment $\left(4 \mathrm{I}^{-}+\mathrm{O}_{2}+4 \mathrm{H}^{+} \rightleftharpoons 2 \mathrm{I}_{2}+\right.$ $\left.2 \mathrm{H}_{2} \mathrm{O}\right)$. On the other hand, the data of Ivanov et al. ${ }^{35}$ are in reasonable agreement with the ones reported by Brunetti et al. ${ }^{7}$ using Knudsen effusion mass spectroscopy (no solvents involved) and also with DFT calculations, ${ }^{6}$ despite the expected overestimation of the formation enthalpy in DMSO (which may be rather small). Thus, we chose to use their formation enthalpy values for hybrid halide perovskites to draw further conclusions on intrinsic and extrinsic degradation processes.

Intrinsic Stability at Elevated Temperatures. Having treated the intrinsic phase stability at room temperature, we now discuss the stability at elevated temperatures. In order to identify the thermodynamically dominant decomposition pathway, we consider three relevant reactions:

$$
\begin{aligned}
& \mathrm{CH}_{3} \mathrm{NH}_{3} \mathrm{PbX}_{3} \rightleftharpoons \mathrm{CH}_{3} \mathrm{NH}_{3} \mathrm{X}+\mathrm{PbX}_{2} \\
& \mathrm{CH}_{3} \mathrm{NH}_{3} \mathrm{PbX}_{3} \rightleftharpoons \mathrm{CH}_{3} \mathrm{NH}_{2}+\mathrm{HX}+\mathrm{PbX}_{2} \\
& \mathrm{CH}_{3} \mathrm{NH}_{3} \mathrm{PbX}_{3} \rightleftharpoons \mathrm{CH}_{3} \mathrm{X}+\mathrm{NH}_{3}+\mathrm{PbX}_{2}
\end{aligned}
$$

Equation 1 is the degradation of $\mathrm{CH}_{3} \mathrm{NH}_{3} \mathrm{PbX}_{3}$ into the solid halide precursors. Equation 2 differs from eq 1 by adding the dissociation of $\mathrm{CH}_{3} \mathrm{NH}_{3} \mathrm{X}$ in $\mathrm{CH}_{3} \mathrm{NH}_{2}$ and $\mathrm{HX}$, while eq 3 differs by considering $\mathrm{CH}_{3} \mathrm{NH}_{3} \mathrm{X}$ breaking into $\mathrm{NH}_{3}$ and $\mathrm{CH}_{3} \mathrm{X}$. Figure 2 shows the formation energies of $\mathrm{CH}_{3} \mathrm{NH}_{3} \mathrm{PbX}_{3}$ for these different pathways as a function of temperature (stability trends of the different pathways as a function of the halide are given in Figure S3). Note that we give here standard formation free energies $\left(\Delta_{\mathrm{f}} G^{0}\right)$, i.e., free energy changes that refer to the above degradation reactions taken in reverse (from right to left). Such values are obtained by assuming equilibrium systems and all compounds involved to be in their standard state (i.e., gaseous components' partial pressures of 1 bar). The comparison between different thermodynamic data for halide 

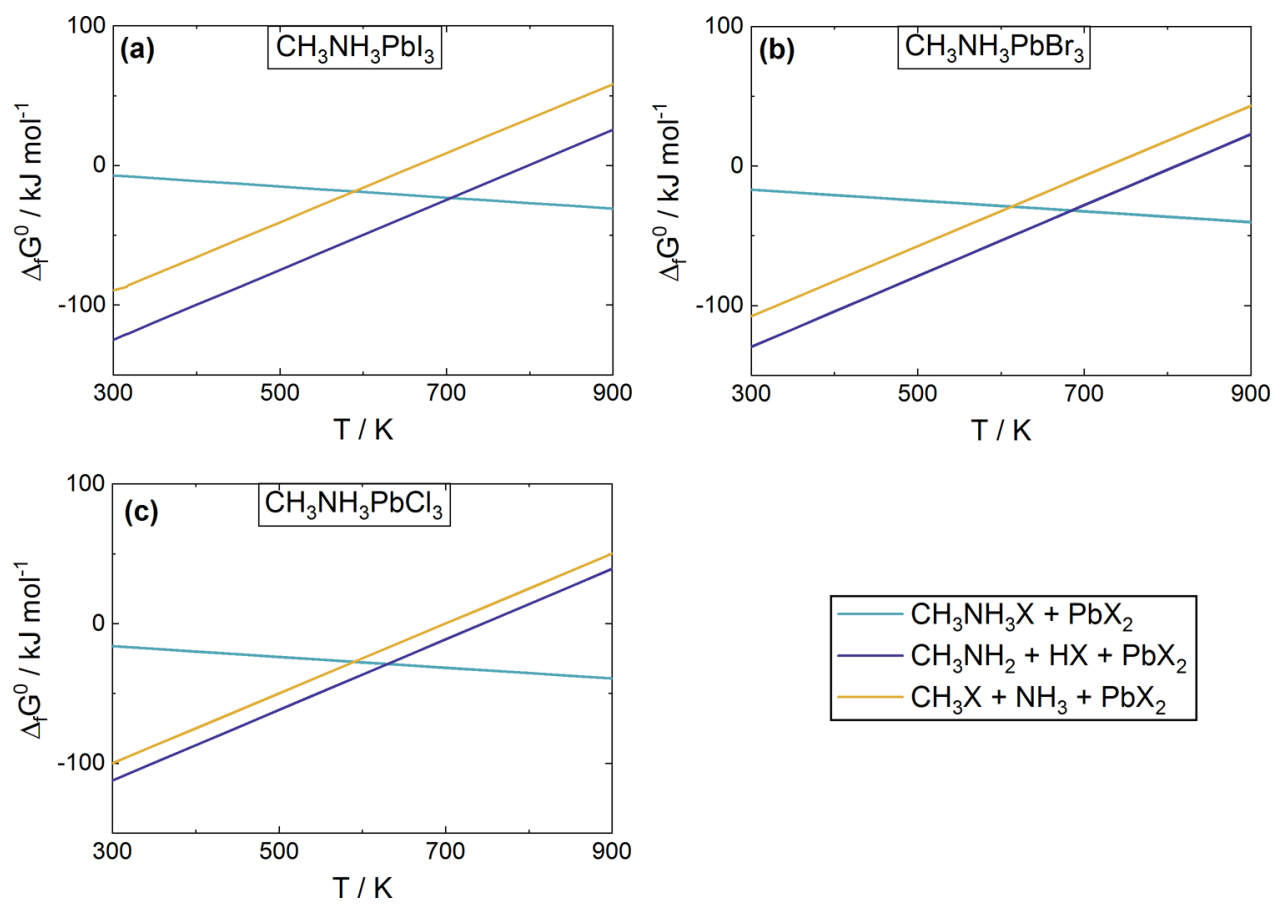

Figure 2. Comparison of the three degradation pathways for (a) $\mathrm{CH}_{3} \mathrm{NH}_{3} \mathrm{PbI}_{3}$, (b) $\mathrm{CH}_{3} \mathrm{NH}_{3} \mathrm{PbBr}_{3}$, and (c) $\mathrm{CH}_{3} \mathrm{NH}_{3} \mathrm{PbCl}_{3}$. Data represent free formation energies assuming all gaseous components in the standard state (partial pressure $=1$ bar). Thermodynamic data for halide perovskites were taken from ref 35 .

perovskites is given in Tables $1-3$. As $\Delta_{\mathrm{f}} S^{0}$ of eq 1 is positive, it is clear that eq 1 describes an entropically stabilized process,

Table 2. Enthalpy, Entropy, and Gibbs Energy of Formation of $\mathrm{MAPbX}_{3}$ with Respect to Methylamine and Hydrogen Halides $\left(\mathrm{CH}_{3} \mathrm{NH}_{2}+\mathrm{HX}+\mathrm{PbI}_{2}\right)$, Calculated at $\mathrm{T}=298 \mathrm{~K}$ and Assuming All Compounds in Their Standard State ${ }^{a}$

$\begin{array}{cccc}\text { compound } & \Delta_{\mathrm{f}} \mathrm{H}^{0} / \mathrm{kJ} \cdot \mathrm{mol}^{-1} & \Delta_{\mathrm{f}} S^{0} / \mathrm{J} \cdot \mathrm{mol}^{-1} \cdot \mathrm{K}^{-1} & \Delta_{\mathrm{f}} \mathrm{G}^{0} / \mathrm{kJ} \cdot \mathrm{mol}^{-1} \\ \mathrm{MAPbI}_{3} & -204.2^{1} & -250.7 & -129.5 \\ & -170.1^{2} & & -95.4 \\ \mathrm{MAPbBr}_{3} & -200.1^{3} & & -125.4 \\ & -202.1^{1} & -253.8 & -126.4 \\ & -192.1^{2} & & -116.4 \\ \mathrm{MAPbCl}_{3} & -205.6^{3} & & -129.9 \\ & -186.3^{1} & -252.3 & -111.0 \\ & -192.5^{2} & & -117.2 \\ & -188.0^{3} & & -112.7\end{array}$

${ }^{a}$ Entropy values were calculated using tabulated data, in conjunction with halide perovskite values found in ref 38 .

and as such formation becomes more favorable at higher temperatures (correspondingly, degradation through this path is less favored upon heating). This conforms to the absence of experimental observation on the demixing of halide perovskites into solid halide precursors.

More interestingly, as shown in Figure 2, eqs 2 and 3 have formation energies that increase with temperature; thus, it is possible to predict degradation at $T \approx 750-800 \mathrm{~K}$ if assuming all gaseous components to be in the standard state (i.e., to have a partial pressure of $1 \mathrm{bar}$ ). Under this assumption, there is only a minor difference between the energetics of eqs 2 and 3, with the latter being slightly energetically favored as a degradation pathway (especially for $\mathrm{CH}_{3} \mathrm{NH}_{3} \mathrm{PbI}_{3}$ ). Nonetheless, the situation is expected to drastically change under real
Table 3. Enthalpy, Entropy, and Gibbs Energy of Formation of $\mathrm{MAPbX}_{3}$ with Respect to Methyl Halides and Ammonia $\left(\mathrm{CH}_{3} \mathrm{X}+\mathrm{NH}_{3}+\mathrm{PbI}_{2}\right)$, Calculated at $\mathrm{T}=298 \mathrm{~K}$ and Assuming All Compounds in Their Standard State ${ }^{a}$

$\begin{array}{lccc}\text { compound } & \Delta_{\mathrm{f}} H^{0} / \mathrm{kJ} \cdot \mathrm{mol}^{-1} & \Delta_{\mathrm{f}} S^{0} / \mathrm{J} \cdot \mathrm{mol}^{-1} \cdot \mathrm{K}^{-1} & \Delta_{\mathrm{f}} \mathrm{G}^{0} / \mathrm{kJ} \cdot \mathrm{mol}^{-1} \\ \mathrm{MAPbI}_{3} & -140.7^{1} & -156.8 & -94.0 \\ & -106.6^{2} & & -59.9 \\ & -136.6^{3} & & -89.9 \\ \mathrm{MAPbBr}_{3} & -179.6^{1} & -251.4 & -104.6 \\ & -169.6^{2} & & -94.7 \\ & -183.1^{3} & & -108.1 \\ \mathrm{MAPbCl}_{3} & -173.3^{1} & -249.9 & -98.8 \\ & -179.5^{2} & & -105.0 \\ & -175.0^{3} & & -100.4\end{array}$

${ }^{a}$ Entropy values were calculated using tabulated data, in conjunction with halide perovskite values found in ref 38 .

conditions due to several gaseous degradation products (e.g., $\mathrm{CH}_{3} \mathrm{NH}_{2}, \mathrm{HX}, \mathrm{NH}_{3}$ ) lacking a perceptible partial pressure in a common laboratory environment. Owing to this, we expect both eqs 2 and 3 to be relevant degradation pathways at much lower temperatures under real conditions. In this respect, we note that lowering the partial pressure of one of the gaseous components by 1 order of magnitude results in an increase of Gibbs formation energy of $5.7 \mathrm{~kJ} / \mathrm{mol}$ at $298 \mathrm{~K}$ (higher temperatures yield even higher values). As such, partial pressures of $\mathrm{CH}_{3} \mathrm{NH}_{2}$ and $\mathrm{HX}$ (or of $\mathrm{CH}_{3} \mathrm{X}$ and $\mathrm{NH}_{3}$ ) on the order of $10^{-11}$ bar (which are not unrealistic) would be sufficient to turn the formation energy of $\mathrm{MAPbX}_{3}$ according to eq 2 (or to eq 3 ) into a positive value at room temperature. Moreover, as also noted elsewhere, ${ }^{36}$ despite the involved energy gain, it is reasonable to expect that the breaking of a C$\mathrm{N}$ bond (as formulated by eq 3 ) will be kinetically hindered at low temperatures, making eq 2 a more viable decomposition 
pathway. Indeed, this reaction has been experimentally observed. ${ }^{1,5}$ Nonetheless, when decomposing halide perovskites at higher temperatures (or under catalytic conditions), where the kinetics of $\mathrm{C}-\mathrm{N}$ bond breaking is not limiting, a decomposition through eq 3 can instead be detected, ${ }^{49}$ as thermodynamically expected. In this respect, the main difference between the experimental observations of the reactions of eqs 2 and 3 (refs 1,5 , and 49, respectively) as dominant degradation pathways may arise from different experimental conditions, in particular heating rate, vacuum pressure, oxygen content (see next section), microstructural features, and presence of residual solvents from the synthesis step. This hypothesis was also proposed elsewhere. ${ }^{50}$ The above conclusions hold for all three hybrid halide perovskites, as shown in Figure 2, the only point of interest being that the energetic disparity between the degradation according to eqs 2 and 3 becomes even smaller when going from $\mathrm{I}$ to $\mathrm{Br}$ to $\mathrm{Cl}$.

In general, the intrinsic instability with respect to temperature is primarily related to the organic cation of the hybrid perovskite structure (as evidenced by the small difference in the degradation energy between the three halides). As such, it is reasonable to expect that both eqs 2 and 3 could be drastically different for different A-cations. Owing to a lower tendency toward deprotonation, ${ }^{51}$ we would, for example, expect formamidinium lead iodide $\left(\mathrm{FAPbI}_{3}\right)$ to show a higher stability with respect to $\mathrm{MAPbI}_{3}$ (especially toward eq 2). This is indeed experimentally observed. ${ }^{10,52}$ Unfortunately, no further conclusions can be drawn due to the lack of thermodynamic data on $\mathrm{FAPbI}_{3}$.

\section{The intrinsic instability with respect to temperature is primarily related to the organic cation of the hybrid perovskite structure.}

Extrinsic Stability vs $\mathrm{O}_{2}$. More effective decomposition processes involve the reaction with extrinsic components such as $\mathrm{O}_{2}, \mathrm{H}_{2} \mathrm{O}$, or contact phases. Considering the stability with respect to $\mathrm{O}_{2}$, it is straightforward to consider a formation/decomposition reaction of the form

$$
\begin{aligned}
& \mathrm{CH}_{3} \mathrm{NH}_{3} \mathrm{PbX}_{3}+\frac{1}{4} \mathrm{O}_{2} \\
& \rightleftharpoons \frac{1}{2} \mathrm{H}_{2} \mathrm{O}+\frac{1}{2} \mathrm{X}_{2}+\mathrm{CH}_{3} \mathrm{NH}_{2}+\mathrm{PbX}_{2}
\end{aligned}
$$

According to eq 4, $\mathrm{O}_{2}$ deprotonates $\mathrm{CH}_{3} \mathrm{NH}_{3}{ }^{+}$, and yields methylamine, water, and halide molecules. This reaction was also suggested elsewhere. ${ }^{17}$ The relevance of eq 4 can be deduced as follows: the decomposition of $\mathrm{MAPbX}_{3}$ via eq 2 is endergonic $\left(\Delta_{\mathrm{f}} G^{0}>0\right)$ as it is the decomposition involving $\mathrm{H}_{2}$ and $\mathrm{X}_{2}$ as products instead of $\mathrm{HX}$ ( $\mathrm{HI}$ has only a very small $\Delta_{\mathrm{f}} G^{0}$ of $1.5 \mathrm{~kJ} / \mathrm{mol}$ with respect to $\mathrm{H}_{2}$ and $\mathrm{I}_{2}$ ). The coupling of $\mathrm{H}_{2}$ with $\mathrm{O}_{2}$ to form water though, as expressed by eq 4, provides a strong driving force toward degradation. We note that in the case of $\mathrm{MAPbI}_{3}$ oxygen can also react with $\mathrm{PbI}_{2}$ and form $\mathrm{PbO}$, with a further (but small) energy gain toward decomposition $\left(\mathrm{PbBr}_{2}\right.$ and $\mathrm{PbCl}_{2}$ are instead stable against $\mathrm{O}_{2}$ ). The formation of $\mathrm{PbO}$, however, was never experimentally observed, obviously due to kinetic considerations, and as such we do not consider it. Similarly, the oxygenation of $\mathrm{CH}_{3} \mathrm{NH}_{2}$, even though exergonic, is not expected to occur for kinetic reasons. Using tabulated data, we calculate the energetics of eq 4 (Table 4). It is clear that the situation is

Table 4. Enthalpy, Entropy, and Gibbs Energy of Formation of $\mathrm{MAPbX}_{3}$ with Oxygen (eq 4$)^{a}$

$\begin{array}{lcccc}\text { compound } & \begin{array}{c}\Delta_{\mathrm{f}} \mathrm{H}^{0} / \\ \mathrm{kJ} \cdot \mathrm{mol}^{-1}\end{array} & \begin{array}{c}\Delta_{\mathrm{f}} S^{0} / \\ \mathrm{J} \cdot \mathrm{mol}^{-1} \cdot \mathrm{K}^{-1}\end{array} & \begin{array}{c}\Delta_{\mathrm{f}} \mathrm{G}^{0} / \\ \mathrm{kJ} \cdot \mathrm{mol}^{-1}\end{array} & \begin{array}{c}\Delta_{\mathrm{f}} G^{\text {real }} \\ \mathrm{kJ} \cdot \mathrm{mol}^{-1}\end{array} \\ \mathrm{MAPbI}_{3} & -34.8^{7} & -85.4 & -9.3 & +43.8 \\ & -0.7^{34} & & +24.8 & +77.9 \\ \mathrm{MAPbBr}_{3} & -30.7^{35} & & -5.2 & +47.9 \\ & -95.5^{7} & -115.0 & -61.2 & 0.0 \\ & -85.5^{34} & & -51.2 & +10.0 \\ \mathrm{MAPbCl}_{3} & -135.0^{35} & & -64.7 & -3.5 \\ & -141.9^{34} & -160.7 & -87.8 & -25.0 \\ & -137.4^{35} & & -94.0 & -31.3 \\ & & & -89.5 & -26.7\end{array}$

${ }^{a}$ Standard values were calculated at $T=298 \mathrm{~K}$ and assuming all compounds in their standard state. $\Delta_{\mathrm{f}} G^{\text {real }}$ values were calculated at $298 \mathrm{~K}$, considering $P\left(\mathrm{X}_{2}\right)=P\left(\mathrm{CH}_{3} \mathrm{NH}_{2}\right)=10^{-7}$ bar, $P\left(\mathrm{H}_{2} \mathrm{O}\right)=10^{-3}$ bar $(\sim 3 \% \mathrm{RH})$, and $P\left(\mathrm{O}_{2}\right)=0.1$ bar. Entropy values were calculated using tabulated data, in conjunction with halide perovskite values found in ref 38 .

particularly severe for $\mathrm{MAPbI}_{3}$, where the oxygen presence yields $\Delta_{\mathrm{f}} G^{0}$ values that are barely negative $(-5.2 \mathrm{~kJ} / \mathrm{mol})$, indicating only slight stability. Notably, $\mathrm{MAPbI}_{3}$ appears only weakly destabilized by oxygen when comparing its energetics with respect to its halide precursors (compare Tables 1 and 4).

Recall that these considerations are made by assuming that all compounds participating in the reaction are in their standard state. Under real conditions, this assumption will hold for eq 1 (as it only involves solids) but clearly not for eq 4 due to the participation of gaseous components. We expect therefore that, under real conditions, eq 4 will be much more efficient in degrading $\mathrm{MAPbI}_{3}$ than eq 1 , and that this conclusion will be even more relevant for temperatures higher than room temperature (as eq 1 is entropically stabilized). Indeed, when using a very conservative estimate for the partial pressure of the gaseous compound participating in eq 4 that is found in, e.g., laboratory air, we find that $\mathrm{MAPbI}_{3}$ is expected to be highly unstable under 0.1 bar of oxygen at room temperature $\left(\Delta_{\mathrm{f}} G^{\text {real }}(298 \mathrm{~K})=+47.9 \mathrm{~kJ} / \mathrm{mol}\right.$; see the Supporting Information for details). $\mathrm{MAPbBr}_{3}$ shows negative formation energies (Table 4), even though the values are rather close to 0 . On the contrary, $\mathrm{MAPbCl}_{3}$ shows a decent thermodynamic stability. To make $\mathrm{MAPbI}_{3}$ even slightly stable under the considered conditions, one would need to lower the oxygen partial pressure to at least $10^{-34}$ bar. Note that the $P\left(\mathrm{X}_{2}\right)$ and $P\left(\mathrm{CH}_{3} \mathrm{NH}_{2}\right)$ chosen for the $\Delta_{\mathrm{f}} G^{\text {real }}$ calculations $\left(=10^{-7}\right.$ bar $)$ are likely to be much lower in laboratory air, especially under a dynamic gas flow, making the degradation under oxygen even more severe. As an example, the atmospheric iodine concentration (which is the sum of $I_{2}$, $\mathrm{IO}, \mathrm{IO}_{2}$, etc. $)$ is often found around a few ppt $\left(10^{-12}\right.$ bar $)$ on the mainland and around $10-100 \mathrm{ppt}$ in coastal air. ${ }^{53,54}$ In addition, according to eq 4, we would expect that the halide partial pressure would counteract the oxygen exposure by reducing the tendency for degradation. Indeed, this has been experimentally observed for $\mathrm{MAPbI}_{3}$ in the form of a slower degradation kinetics. ${ }^{55}$ For completeness, and also to provide a more accurate description of the stability under different conditions, we also calculate the Gibbs energy of formation of $\mathrm{MAPbX}_{3}$ according to eq 4 as a function of $\mathrm{P}\left(\mathrm{O}_{2}\right)$ and $T$ and 

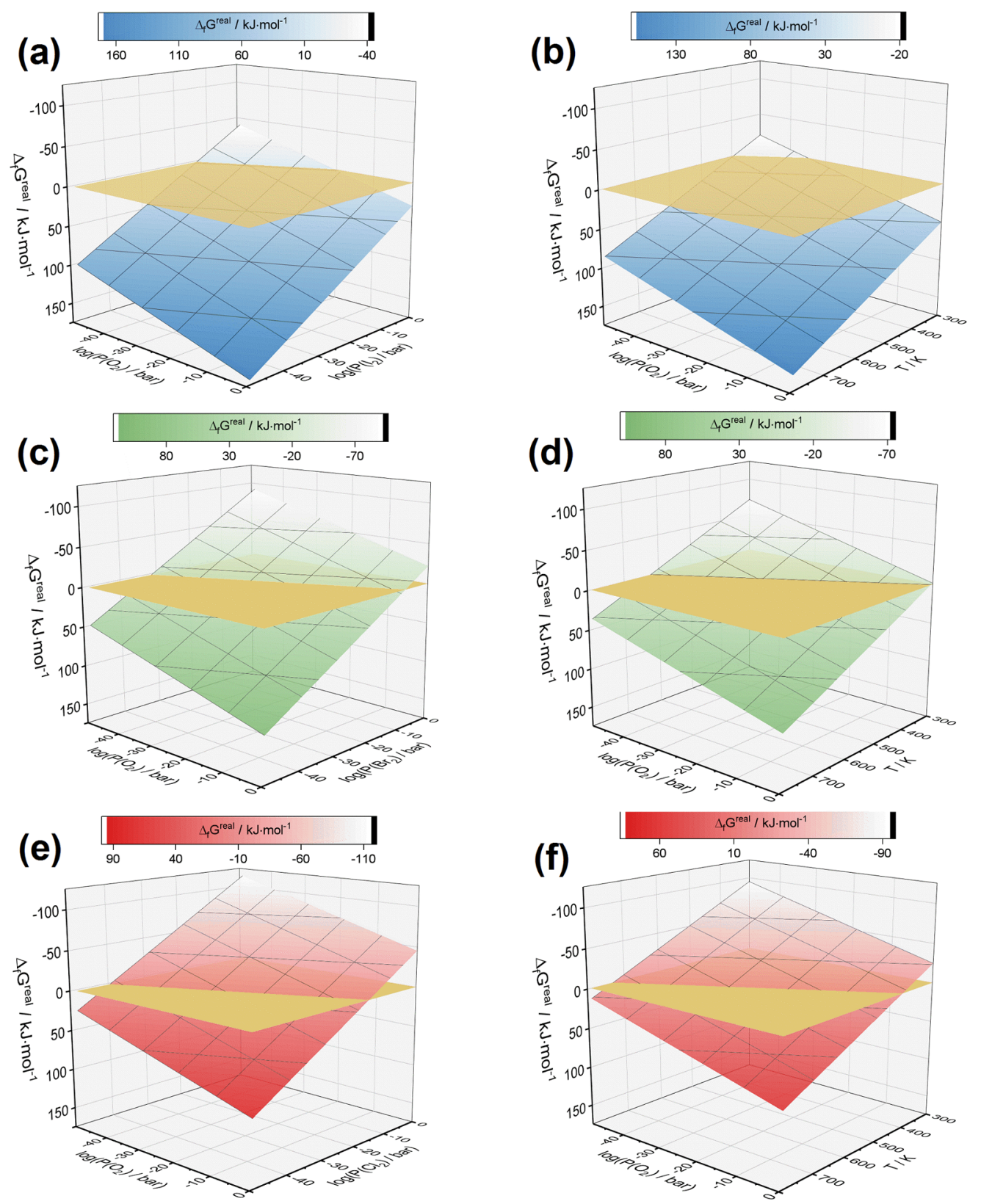

Figure 3. Stability of $\mathrm{MAPbX}_{3}$ according to eq 4 as a function of oxygen and halogen partial pressure (left column, calculated at $298 \mathrm{~K}$, with $P\left(\mathrm{CH}_{3} \mathrm{NH}_{2}\right)=10^{-7}$ bar and $P\left(\mathrm{H}_{2} \mathrm{O}\right)=10^{-3} \mathrm{bar}$ ) and oxygen partial pressure and temperature (right column, calculated assuming $P\left(\mathrm{X}_{2}\right)=$ $P\left(\mathrm{CH}_{3} \mathrm{NH}_{2}\right)=10^{-7}$ bar and $P\left(\mathrm{H}_{2} \mathrm{O}\right)=10^{-3}$ bar). Data for (a,b) $\mathrm{MAPbI}_{3}$ (blue plots), (c,d) $\mathrm{MAPbBr}_{3}$ (green plots), and (e,f) $\mathrm{MAPbCl} \mathrm{C}_{3}(\mathrm{red}$ plots). The yellow plane is used to highlight the stability (above plane) and instability (below plane) regions of the plot.

$P\left(\mathrm{O}_{2}\right)$ and $P\left(\mathrm{X}_{2}\right)$. The resulting contour plots are given in Figure 3 , where the stability trends discussed above are more clearly visible.

\section{$\mathrm{MAPbl}_{3}$ is expected to be highly unstable under 0.1 bar of oxygen at room temperature.}

The extrinsic degradation under oxygen targets both the organic cation and the halide ions (Table 4). Moving from $\mathrm{MAPbI}_{3}$ to $\mathrm{MAPbBr}_{3}$ (or $\mathrm{MAPbCl}_{3}$ ) increases stability. In addition, different A-cations with a lower tendency toward deprotonation may offer a strategy for improving the compound stability. As an example, FA-containing perovskites seem to show a reduced-but still present-tendency for degradation under oxygen. ${ }^{55}$ The impact of this degradation process on solar cells is treated in detail elsewere. ${ }^{56-58}$

Extrinsic Stability vs $\mathrm{H}_{2} \mathrm{O}$. Water-induced decomposition was the first degradation process to be studied for methylammonium halide perovskites. ${ }^{27}$ It has been shown that liquid water can induce leaching of MA cations out of the structure as $\mathrm{H}_{2} \mathrm{O}$ efficiently dissolves MAX while leaving $\mathrm{PbX}_{2}$ intact. ${ }^{6,27} \mathrm{~A}$ similar process takes place under high relative humidity. This is expected as the solubility of MAX is high and the solubility product of $\mathrm{PbX}_{2}$ is rather small. As such, the low Gibbs energy of formation of $\mathrm{MAPbX}_{3}$ with respect to $\mathrm{MAX}$ and $\mathrm{PbX}_{2}$ is easily overcome by the dissolution enthalpy of MAX. Notably, as shown in Figure 4, at low relative humidity, the halide perovskite structure can instead undergo a reversible 


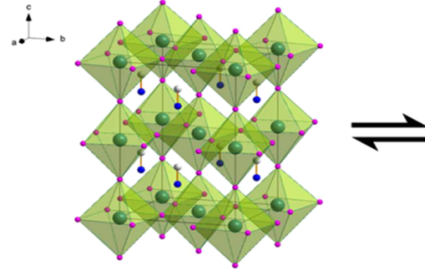

Cubic $\mathrm{CH}_{3} \mathrm{NH}_{3} \mathrm{Pbl}_{3}$

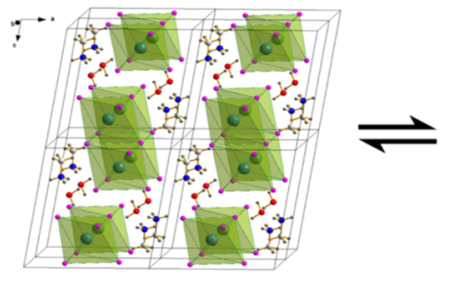

$\mathrm{CH}_{3} \mathrm{NH}_{3} \mathrm{Pbl}_{3} \cdot \mathrm{H}_{2} \mathrm{O}$

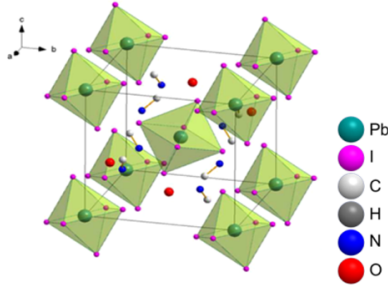

$\left(\mathrm{CH}_{3} \mathrm{NH}_{3}\right)_{4} \mathrm{PbI}_{6} \cdot 2 \mathrm{H}_{2} \mathrm{O}$

Figure 4. Representation of the reversible hydration taking place in $\mathrm{CH}_{3} \mathrm{NH}_{3} \mathrm{PbI}_{3}$ crystals. Two separate phases are identified by $\mathrm{XRD}^{28}$ Adapted with permission from ref 28 .

hydration. ${ }^{28}$ While we have no thermodynamic data for this reaction, it is reasonable to assume that the extrinsic degradation under water is mainly dominated by the ease of dissolution of MAX (or FAX). As such, none of the presently used halides or A-cations (including cesium) are expected to provide significantly better stability against water or moisture. For the readers that are more interested in this degradation mechanism and on its consequence on solar cell stability, we refer to the literature. ${ }^{27,29,30,58-61}$

Stability under Voltage. For mixed ionic-electronic conductors (such as halide perovskites), an important source of

\section{For mixed ionic-electronic conductors (such as halide perovskites), an impor- tant source of instability can be voltage applied by electrodes that block the ions.}

instability can be voltage applied by electrodes that block the ions. In such conditions, the voltage induces in the steady state a difference in the chemical potential of the components that can exceed the material stability limit. This limit is determined by the decomposition voltage (proportional to the Gibbs energy of the decomposition reaction) and not by the field. For halide perovskites, the halogen is the predominantly mobile species; thus, its chemical potential $\left(\mu_{\mathrm{X}}=\tilde{\mu}_{\mathrm{X}^{-}}-\tilde{\mu}_{\mathrm{e}}\right)$ is the most relevant parameter. Applying a voltage will thus induce a variation of $\mu_{\mathrm{X}}$ according to $U_{\text {Steady State }}=-\Delta \mu_{\mathrm{X}} / F\left(\Delta \tilde{\mu}_{\mathrm{X}^{-}}=0\right.$ due to ion-blocking electrodes). For more details, the reader is referred to ref 62 . Taking as an example the decomposition pathway given in eq 2, voltages of $1.3,1.3$, and $1.2 \mathrm{~V}$ are sufficient to degrade $\mathrm{MAPbI}_{3}, \mathrm{MAPbBr}_{3}$, and $\mathrm{MAPbCl}_{3}$, respectively, even assuming all compounds involved in their standard state and at room temperature (see Table 2). Applying higher voltages $\left(2.7 \mathrm{~V}\right.$ for $\mathrm{MAPbI}_{3}, 4.3 \mathrm{~V}$ for $\mathrm{MAPbBr}_{3}, 5.1 \mathrm{~V}$ for $\mathrm{MAPbCl}_{3}$ ) would be even enough to decompose these materials into their elemental components (see Table S1). Considering A-cation or halide mixtures (discussed below), a much lower voltage would be sufficient to overcome the mixing entropy and induce demixing. Under the above bias conditions, degradation will take place, starting from the electrode interfaces. We note that in several reported experiments on halide perovskites voltages are applied that are often in the range of $10-100 \mathrm{~V}$ and as such greatly above the thermodynamically expected decomposition voltages. In halide perovskites, the kinetics of the processes involved in the decomposition is expected to be rather quick (see below for a more detailed discussion on degradation kinetics). A metastable situation - as can be the case for materials with very low ionic conductivities or surface exchange rates-is therefore not expected.

Stability under Illumination. A different-but highly relevant-source of instability is represented by illumination. There are numerous literature reports on photoinduced instability in methylammonium lead halides, ${ }^{9-15}$ albeit the atomistic process is still unclear. One possible photodegradation mechanism, proposed by our group, ${ }^{63}$ is based on the enhanced chemical potential of the halogen $\mathrm{X}$ generated by illumination, which is connected with the photoinduced ion conduction enhancement observed for $\mathrm{MAPbI}_{3}$. Specifically, we proposed that by self-trapping photogenerated electron holes iodine ions could be neutralized and subsequently displaced from regular lattice sites, forming-at least partially-mobile iodine vacancies. This formation of neutral iodine atoms effectively enhances the iodine chemical potential inside of the material, and this can act as the driving force for an iodine flux directed to the outer gas phase or to a sink (Figure 5a). If the halogen is allowed to leave, the equilibrium stoichiometric window may be exceeded and an irreversible degradation will take place (Figure $5 b$ ).
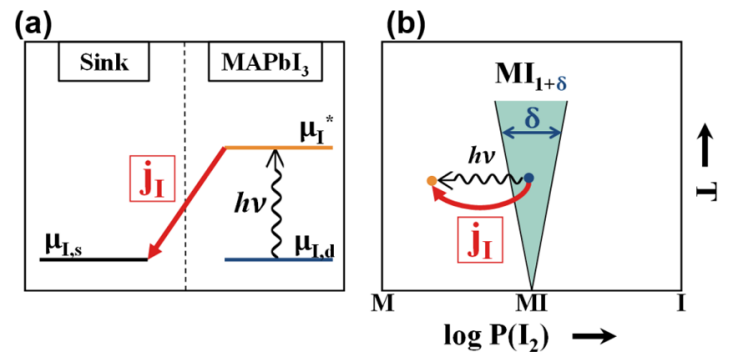

Figure 5. Mechanism for photoinduced instability in MAPbI $_{3}$. (a) After enhancing the iodine chemical potential inside of MAPbI $_{3}$ by light, an iodine flux directed to the outer gas phase (or any sink) will take place. The driving force for this process is the photogenerated difference in chemical potential between the material and the sink $\left(\mu_{\mathrm{I}}^{*}-\mu_{\mathrm{I}, \mathrm{s}}\right)$, which were originally in equilibrium $\left(\mu_{\mathrm{I}, \mathrm{s}}=\mu_{\mathrm{I}, \mathrm{d}}\right)$. (b) The same process can be represented in the phase diagram as a photogenerated stoichiometry change that exceeds the stable compositional window accessible by the material. Figure taken from ref 63.

\section{One possible photodegradation mech- anism is based on the enhanced chemical potential of the halogen $\mathrm{X}$ generated by illumination.}

According to the above mechanism, the extrinsic degradation upon illumination targets primarily the iodide ions. As this 
(a)

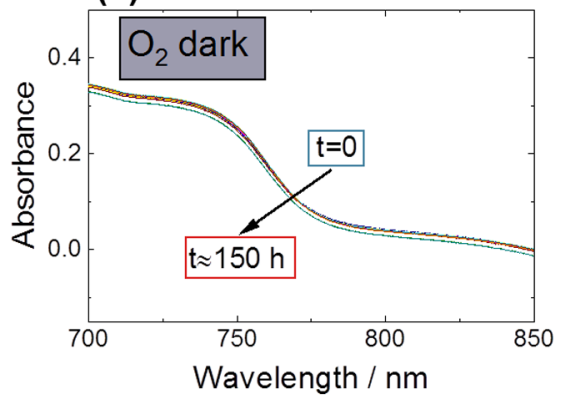

(c)

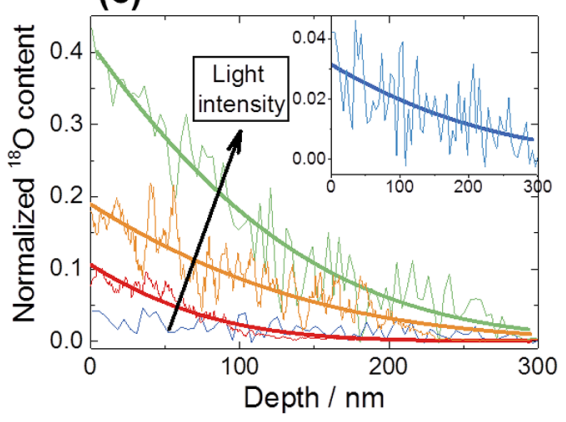

(b)

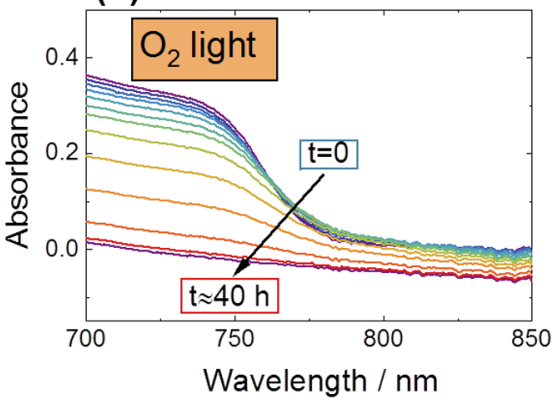

(d)

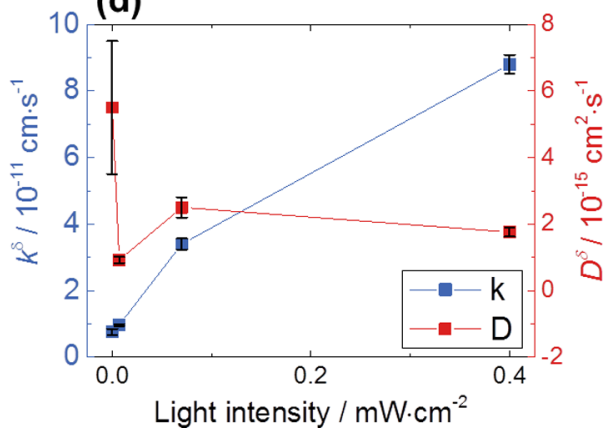

Figure 6. (a,b) Degradation study of $\mathrm{MAPbI}_{3}$ monitored by UV-vis absorption measurements, where a thin film sample is kept under pure oxygen flow at $333 \mathrm{~K}$. In the dark, no degradation is observed after 1 week, while under $4.6 \mathrm{~mW} / \mathrm{cm}^{2}$ of illumination, a complete decomposition takes place in less than $40 \mathrm{~h}$. $(\mathrm{c}, \mathrm{d}){ }^{18} \mathrm{O}$ incorporation experiment, where $\mathrm{MAPbI}_{3}$ thin films are exposed to ${ }^{18} \mathrm{O}_{2}$ at $333 \mathrm{~K}$ and under different light intensities. (c) Diffusion profiles (the inset is a magnification of the dark profile) and (d) corresponding extracted incorporation parameters. Figure adapted from ref 55. Published by The Royal Society of Chemistry.

decomposition mechanism is necessarily present under device operating conditions, it may be necessary to consider different halides $(\mathrm{Br}$ or $\mathrm{Cl})$ for which the light effects may not be as strong due to the different chemistry. This process takes place simultaneously as the oxygen degradation under an $\mathrm{O}_{2}$-rich atmosphere and therefore may be overshadowed by the much stronger oxygen decomposition. Nonetheless, photodecomposition is expected to be relevant even under an inert atmosphere, as long as an exchange of iodine from MAPI to a sink is not kinetically too sluggish.

Extrinsic Stability vs Hole/Electron Transport Materials. A further important source of instability is the reactivity of the halide perovskite with the phases used as electron or hole transport materials in photovoltaic or optoelectronic devices. Thermodynamically, the stability limit in these conditions is set by the reaction channel with the lowest (most negative) Gibbs energy change. As devices are not in the focus of this contribution and due to the lack of thermodynamic information, we will only mention these aspects briefly for completeness sake. For example, in typical perovskite solar cells, mesoporous $\mathrm{TiO}_{2}$ is used as the electron transport material, while organic compounds (spiro-OMeTAD, PTAA, P3HT, PEDOT:PSS, etc.) are used as hole transport materials. $\mathrm{TiO}_{2}$ is known to cause device instability due to its photoactivity under UV irradiation and the presence of trap states, ${ }^{64}$ but it is unclear if it has a direct impact on the degradation of the halide perovskite layer itself. Instead, and more importantly, organic hole transport materials are often either doped with lithium salts (spiro-OMeTAD, PTAA) or naturally hygroscopic (PEDOT:PSS), and as such, they incorporate harmful moisture that decomposes the halide perovskite layer. ${ }^{65}$ Another possible source of instability may come directly from the intercalation of $\mathrm{Li}$ ions into the perovskite bulk. ${ }^{66}$ Lastly, these phases may have the ability to dissolve the perovskite components as a consequence of perovskite degradation or simply upon contact. A notable example is the incorporation of iodine coming from $\mathrm{MAPbI}_{3}$ into the hole transport material (as a consequence of aging or of oxygen exposure) ${ }^{56,67-70}$ which may irreversibly affect its transport properties and thus device performance. We refer the interested readers to the literature for a more detailed account of these processes, in particular as far as solar cell stability issues are concerned. ${ }^{57,58,71-73}$

Degradation Kinetics. So far, a clear thermodynamic picture was developed for the above decomposition mechanisms, which is consistent with experimental observations. Nonetheless, under real conditions, degradation kinetics is decisive for the material's effective stability. The rate-determining step may differ for the various decomposition modes, and it may involve bulk diffusion of species, surface exchange processes, and even higher dimensional defects. Owing to the lack of detailed information on most of the above-mentioned decomposition processes and to the complexity of chemical reaction kinetics, these aspects will be dealt with on a rather general level.

Bulk diffusion of ionic species is known to be of relevance for the kinetics of incorporation/dissolution of species in the solid state. Of equal importance is the surface reaction, which represents the first/last step in an incorporation/dissolution process. A more extensive treatment of these aspects is given elsewhere. ${ }^{62,74}$ Here we just underline that halide perovskites have been extensively shown to be anion conductors, ${ }^{75-78}$ with substantial diffusion coefficients even at room temperature. In addition, in methylammonium-based perovskites, perceptible-albeit rather small-methylammonium diffusion is also observable. ${ }^{79}$ As these materials are mixed conductors, effective motion of the respective neutral components is feasible. Such 
diffusion processes are involved in the formation kinetics of halide perovskites from their solid precursors (e.g., mechanosynthesis $)^{39-41}$ but also in postsynthetic treatments such as halide $^{80}$ or organic cation ${ }^{81}$ exchanges. Assuming the bulk ionic diffusion ( of $\mathrm{I}^{-}$or $\mathrm{MA}^{+}$) to be the rate-determining step in the degradation kinetics, this appears sufficiently quick to provide no serious kinetic barrier for the degradation of methylammonium-based halide perovskites, at least in the temperature range of device operation. More detailed considerations are given in the Supporting Information.

Surface reaction kinetics has been shown to be of particular relevance for the oxygen interaction with halide perovskites. ${ }^{55}$ As shown in Figure 6a, despite a strong thermodynamic driving force toward decomposition (see above, e.g., Table 4), $\mathrm{MAPbI}_{3}$ does not degrade under oxygen if kept in the dark. Oppositely, under even moderate light intensities (Figure 6b), a swift degradation is observed, indicating a significant light effect on the interaction kinetics. Consistently, experimental evidence shows that the effects of oxygen exposure (e.g., photoluminescence enhancement, oxygen doping) strongly differ with or without illumination. ${ }^{17,55,82}$

Indeed, direct experimental evidence of such an effect can be obtained by ${ }^{18} \mathrm{O}$ incorporation experiments, ${ }^{55}$ where one observes a light-dependent quantity of oxygen being incorporated in $\mathrm{MAPbI}_{3}$ (Figure 6c,d). An in-depth analysis reveals that the kinetics of the surface reaction is greatly accelerated by light. The effect is so significant that in the dark the oxygen interaction is blocked by the surface and the material does not incorporate any significant amount of oxygen, remaining metastable. ${ }^{55}$ This surface-blocking behavior is not encountered when considering $\mathrm{I}_{2}$ exchange; ${ }^{55,83}$ this difference in the exchange kinetics can be ascribed to the different energies involved in the bond breaking of the $\mathrm{O}_{2}$ and $\mathrm{I}_{2}$ gaseous molecules. The kinetic hindrance involving the $\mathrm{O}_{2}$ interaction, while seemingly strong, is removed by light and thus cannot be exploited in devices under operation.

Stability of Anionic and Cationic Mixtures. So far, the focus was on hybrid halide perovskites of simple ternary composition, but these compounds can be also synthesized with a mixture of ions on the A-site or on the X-site. As these mixtures represent the state of the art in terms of photovoltaic performances, we will also address them here briefly. It is of course expected that the free energy of mixing would stabilize the mixtures (cationic and/or anionic) with respect to all above decomposition pathways. While we have no information on the mixing enthalpy, we can estimate the ideal mixing entropy, which for a 50:50 solid solution of cations or anions is $1.7 \mathrm{~kJ} / \mathrm{mol}$ at $298 \mathrm{~K}$. Considering the small Gibbs energy of formation of the halide perovskites (Table 1), the tiny value of the mixing entropy may still provide a perceptible contribution to the intrinsic stability. As discussed in detail just below, this stabilization is indeed experimentally observed.

Cationic mixtures typically feature a combination of MA and FA (formamidinium) cations, occasionally with the addition of inorganic Cs or Rb. ${ }^{84}$ Usually, these quadruple cation mixtures are reported to be more stable than pure $\mathrm{MAPbI}_{3}$; however, it is likely that this does not stem from their different chemistry but rather from the lack of phase homogeneity (perovskite surface passivated by a secondary phase). ${ }^{85}$ Single-phase mixtures of MA and FA (as well as pure $\mathrm{FAPbI}_{3}$ ) show enhanced stability under device operating conditions, and this may be due not only to the mixing free energy but also to the lower tendency toward deprotonation of FA with respect to
MA. ${ }^{51}$ This would be particularly relevant for the degradation pathways of eq 2 (intrinsic degradation releasing $\mathrm{CH}_{3} \mathrm{NH}_{2}$ ) and eq 4 (oxygen degradation). It is not yet known whether a selective deprotonation process would be of significance for these cationic mixtures. Unfortunately, no further conclusions can be drawn due to the lack of thermodynamic data on $\mathrm{FAPbI}_{3}$.

As far as anionic mixtures are concerned, these are composed primarily of $\mathrm{I}$ and $\mathrm{Br}$ and also show enhanced stability with respect to the pure iodide. Considering formulations such as $\mathrm{MAPb}\left(\mathrm{I}_{x}, \mathrm{Br}_{1-x}\right)_{3}$, the previous thermodynamic considerations already show that pure $\mathrm{MAPbBr}_{3}$ is expected to be more stable than its iodide counterpart toward all temperature- or oxygen-induced decomposition mechanisms. As the solid solution between $\mathrm{MAPbBr}_{3}$ and $\mathrm{MAPbI}_{3}$ seems to be completely miscible (all compositions can be synthesized), it necessarily follows that mixtures with higher bromine content will be the most stable configurations, both with respect to the end components of the phase diagram and also with respect to mixtures with higher iodine content. This also explains why substitution by $\mathrm{Br}$, even at relatively low concentrations, in $\mathrm{MAPbI}_{3}$ improves its stability. Considering their extrinsic degradation under oxygen, however, anionic mixtures of $\mathrm{I}$ and $\mathrm{Br}$ appear unstable as they undergo a selective oxidation of iodide ions yielding pure $\mathrm{MAPbBr}_{3}{ }^{55}$ Obviously the configurational mixing effect does not suffice to stabilize the materials under such conditions.

A more interesting aspect of the anionic mixtures is their tendency to reversibly separate under illumination, ${ }^{86}$ yielding Br-rich and I-rich phases. Brivio et al. ${ }^{87}$ proposed a demixing mechanism that relies on the presence of a miscibility gap in the $\mathrm{I}-\mathrm{Br}$ solid solution at room temperature and below. In this picture, the light provides the energy needed to overcome the kinetic barrier for solid-state diffusion through local heating, resulting in the demixing. While this process can explain the phase separation, it fails to account for the reversibility upon turning off the light. Instead, the demixing process can be straightforwardly explained in the framework of the light effects on stoichiometry discussed previously. ${ }^{63}$ It is reasonable to assume that light effects and the interaction between lattice ions and electronic carriers will strongly differ in the case of I or $\mathrm{Br}$, and as such, illumination will introduce an asymmetric situation leading to a light-induced miscibility gap. Upon turning off the light, the situation can revert to the initial state, with the phase-separated domains remixing due to the Gibbs energy of mixing. Whether this phenomenon is sufficient to explain the experimental demixing results has to be discussed in more details (a more thorough account is presently being prepared). ${ }^{88}$

In conclusion, we can state that, from a thermodynamics point of view, the extrinsic degradation vs water and/or oxygen appears to be most severe. Nonetheless, practical strategies exist to avoid contact between the hybrid halide perovskites and the degrading agents. For example, encapsulation has been proved effective, as well as the use of passivation layers composed of oxides or of hydrophobic molecules. 2D perovskites appear also suitable in passivating their $3 \mathrm{D}$ counterpart in $2 \mathrm{D} / 3 \mathrm{D}$ composites. ${ }^{89}$ More worrisome are the intrinsic instability and the photoinstability, which are hardly avoidable in devices under operation. Encapsulation could potentially help in both cases by preventing the loss of gaseous constituents due to the buildup of a component partial pressure. However, the formation of high-pressure gaseous 
bubbles underneath of the encapsulation layer due to perovskite decomposition has already been observed (albeit under high bias) ${ }^{90}$ and should therefore be taken into account. Another issue is that in devices the electron- and/or holetransport materials may incorporate (or react with) the components lost by the perovskite. ${ }^{56,67-70}$ This could prevent the buildup of a significant component partial pressure, thus reducing the usefulness of the encapsulation. In addition, such occurrence could irreversibly decrease the charge extraction and/or charge transport properties of the transport materials, hence affecting cell performance. It must also be noticed that all of the considerations given in this contribution are based on the bulk properties of hybrid halide perovskites. We can however expect that higher dimensional defects (grain boundaries, dislocations, etc.) will also play an important role, especially in the degradation kinetics, and that these might contribute in the direction of a faster decomposition. The same can be said for any substantial electrical stress that the halide perovskites is subjected to. On the basis of these considerations, it would appear that there is no simple solution for these severe stability problems. Considering new perovskite formulations, exploiting lower dimensionalities, protective layers, and alternative contact phases, as well as finding ways to slow down the degradation kinetics by appropriate doping may bring us closer to the stability goals necessary for commercialization. Given the severity of these decomposition processes, however, it would not be surprising if a combination of all of these approaches will ultimately be required.

\section{ASSOCIATED CONTENT}

\section{S Supporting Information}

The Supporting Information is available free of charge on the ACS Publications website at DOI: 10.1021/acsenergylett.9b01605.

Tables showing the formation energetics of halide perovskites with respect to the elements and photos documenting the aging of $\mathrm{MAI}$ solution in $\mathrm{HCl}$; calculation methods used to obtain the thermodynamic data and the mean square displacement caused by ionic diffusion (PDF)

\section{AUTHOR INFORMATION}

\section{Corresponding Author}

*E-mail: alessandro.senocrate@googlemail.com.

\section{ORCID}

Alessandro Senocrate: 0000-0002-0952-0948

Michael Grätzel: 0000-0002-0068-0195

Joachim Maier: 0000-0003-2274-6068

\section{Notes}

The authors declare no competing financial interest.

\section{Biographies}

Alessandro Senocrate is a Scientist at the Max Planck Institute for Solid State Research in Stuttgart. He earned is Ph.D. in Chemistry from EPFL in 2018, working on understanding ion transport in halide perovskites for photovoltaics. His research topics of interest concern materials for renewable energy conversion and storage.

Gee Yeong Kim received her Ph.D. in Physics from Ewha Womans University, Seoul, in 2016. She joined the Max Planck Institute for Solid State Research in Stuttgart as a Research Scientist in 2016. Her research topics of interest are electronic properties of semiconductors and charge carrier transport in materials for energy conversion and storage.

Michael Grätzel is a Professor at the Ecole Polytechnique Federale de Lausanne. He pioneered research on energy and electron transfer reactions in mesoscopic materials and their application in solar energy conversion systems, i.e., dye-sensitized solar cells, optoelectronic devices, and lithium ion batteries. He is one of the 10 most highly cited chemists worldwide and the recipient of numerous prestigious awards.

Joachim Maier is director of the department of Physical Chemistry of Solids at the Max Planck Institute for Solid State Research in Stuttgart. His interests lie in the field of ion motion in solids. The research ranges from fundamentals of thermodynamics, transport theory, and electrochemistry to applications in the field of energy research.

\section{ACKNOWLEDGMENTS}

The authors are grateful to Dr. Rotraut Merkle for many helpful discussions and to Yaru Wang for experimental assistance.

\section{REFERENCES}

(1) Dualeh, A.; Gao, P.; Seok, S. Il; Nazeeruddin, M. K.; Grätzel, M. Thermal Behavior of Methylammonium Lead-Trihalide Perovskite Photovoltaic Light Harvesters. Chem. Mater. 2014, 26 (21), 61606164.

(2) Conings, B.; Drijkoningen, J.; Gauquelin, N.; Babayigit, A.; D’Haen, J.; D’Olieslaeger, L.; Ethirajan, A.; Verbeeck, J.; Manca, J.; Mosconi, E.; et al. Intrinsic Thermal Instability of Methylammonium Lead Trihalide Perovskite. Adv. Energy Mater. 2015, 5 (15), 1500477.

(3) Han, Y.; Meyer, S.; Dkhissi, Y.; Weber, K.; Pringle, J. M.; Bach, U.; Spiccia, L.; Cheng, Y.-B. Degradation Observations of Encapsulated Planar $\mathrm{CH}_{3} \mathrm{NH}_{3} \mathrm{PbI}_{3}$ Perovskite Solar Cells at High Temperatures and Humidity. J. Mater. Chem. A 2015, 3 (15), 81398147.

(4) Divitini, G.; Cacovich, S.; Matteocci, F.; Cinà, L.; Di Carlo, A.; Ducati, C. In Situ Observation of Heat-Induced Degradation of Perovskite Solar Cells. Nat. Energy 2016, 1 (2), 15012.

(5) Nenon, D. P.; Christians, J. A.; Wheeler, L. M.; Blackburn, J. L.; Sanehira, E. M.; Dou, B.; Olsen, M. L.; Zhu, K.; Berry, J. J.; Luther, J. M. Structural and Chemical Evolution of Methylammonium Lead Halide Perovskites during Thermal Processing from Solution. Energy Environ. Sci. 2016, 9 (6), 2072-2082.

(6) Tenuta, E.; Zheng, C.; Rubel, O. Thermodynamic Origin of Instability in Hybrid Halide Perovskites. Sci. Rep. 2016, 6 (1), 37654.

(7) Brunetti, B.; Cavallo, C.; Ciccioli, A.; Gigli, G.; Latini, A. On the Thermal and Thermodynamic (In)Stability of Methylammonium Lead Halide Perovskites. Sci. Rep. 2016, 6, 31896.

(8) Kim, N.-K.; Min, Y. H.; Noh, S.; Cho, E.; Jeong, G.; Joo, M.; Ahn, S.-W.; Lee, J. S.; Kim, S.; Ihm, K.; et al. Investigation of Thermally Induced Degradation in $\mathrm{CH}_{3} \mathrm{NH}_{3} \mathrm{PbI}_{3}$ Perovskite Solar Cells Using In-Situ Synchrotron Radiation Analysis. Sci. Rep. 2017, 7 (1), 4645 .

(9) Abdelmageed, G.; Mackeen, C.; Hellier, K.; Jewell, L.; Seymour, L.; Tingwald, M.; Bridges, F.; Zhang, J. Z.; Carter, S. Effect of Temperature on Light Induced Degradation in Methylammonium Lead Iodide Perovskite Thin Films and Solar Cells. Sol. Energy Mater. Sol. Cells 2018, 174, 566-571.

(10) Murugadoss, G.; Tanaka, S.; Mizuta, G.; Kanaya, S.; Nishino, H.; Umeyama, T.; Imahori, H.; Ito, S. Light Stability Tests of Methylammonium and Formamidinium $\mathrm{Pb}$-Halide Perovskites for Solar Cell Applications. Jpn. J. Appl. Phys. 2015, 54 (8S1), 08KF08.

(11) Pistor, P.; Ruiz, A.; Cabot, A.; Izquierdo-Roca, V. Advanced Raman Spectroscopy of Methylammonium Lead Iodide: Development of a Non-Destructive Characterisation Methodology. Sci. Rep. 2016, 6, 35973. 
(12) Wei, D.; Wang, T.; Ji, J.; Li, M.; Cui, P.; Li, Y.; Li, G.; Mbengue, J. M.; Song, D. Photo-Induced Degradation of Lead Halide Perovskite Solar Cells Caused by the Hole Transport Layer/Metal Electrode Interface. J. Mater. Chem. A 2016, 4 (5), 1991-1998.

(13) Nickel, N. H.; Lang, F.; Brus, V. V.; Shargaieva, O.; Rappich, J. Unraveling the Light-Induced Degradation Mechanisms of $\mathrm{CH}_{3} \mathrm{NH}_{3} \mathrm{PbI}_{3}$ Perovskite Films. Adv. Electron. Mater. 2017, 3 (12), 1700158.

(14) Li, Y.; Xu, X.; Wang, C.; Ecker, B.; Yang, J.; Huang, J.; Gao, Y. Light-Induced Degradation of $\mathrm{CH}_{3} \mathrm{NH}_{3} \mathrm{PbI}_{3}$ Hybrid Perovskite Thin Film. J. Phys. Chem. C 2017, 121 (7), 3904-3910.

(15) Dao, Q.-D.; Tsuji, R.; Fujii, A.; Ozaki, M. Study on Degradation Mechanism of Perovskite Solar Cell and Their Recovering Effects by Introducing $\mathrm{CH}_{3} \mathrm{NH}_{3} \mathrm{I}$ Layers. Org. Electron. 2017, 43, 229-234.

(16) Song, Z.; Wang, C.; Phillips, A. B.; Grice, C. R.; Zhao, D.; Yu, Y.; Chen, C.; Li, C.; Yin, X.; Ellingson, R. J.; et al. Probing the Origins of Photodegradation in Organic-Inorganic Metal Halide Perovskites with Time-Resolved Mass Spectrometry. Sustain. Energy Fuels 2018, 2 (11), 2460-2467.

(17) Aristidou, N.; Sanchez-Molina, I.; Chotchuangchutchaval, T.; Brown, M.; Martinez, L.; Rath, T.; Haque, S. A. The Role of Oxygen in the Degradation of Methylammonium Lead Trihalide Perovskite Photoactive Layers. Angew. Chem., Int. Ed. 2015, 54 (28), 8208-8212.

(18) O’Mahony, F. T. F.; Lee, Y. H.; Jellett, C.; Dmitrov, S.; Bryant, D. T. J.; Durrant, J. R.; O’Regan, B. C.; Graetzel, M.; Nazeeruddin, M. K.; Haque, S. A. Improved Environmental Stability of Organic Lead Trihalide Perovskite-Based Photoactive-Layers in the Presence of Mesoporous $\mathrm{TiO}_{2}$. J. Mater. Chem. A 2015, 3 (14), 7219-7223.

(19) Tang, X.; Brandl, M.; May, B.; Levchuk, I.; Hou, Y.; Richter, M.; Chen, H.; Chen, S.; Kahmann, S.; Osvet, A.; et al. Photoinduced Degradation of Methylammonium Lead Triiodide Perovskite Semiconductors. J. Mater. Chem. A 2016, 4 (41), 15896-15903.

(20) Bryant, D.; Aristidou, N.; Pont, S.; Sanchez-Molina, I.; Chotchunangatchaval, T.; Wheeler, S.; Durrant, J. R.; Haque, S. A. Light and Oxygen Induced Degradation Limits the Operational Stability of Methylammonium Lead Triiodide Perovskite Solar Cells. Energy Environ. Sci. 2016, 9 (5), 1655-1660.

(21) Pearson, A. J.; Eperon, G. E.; Hopkinson, P. E.; Habisreutinger, S. N.; Wang, J. T.-W.; Snaith, H. J.; Greenham, N. C. Oxygen Degradation in Mesoporous $\mathrm{Al}_{2} \mathrm{O}_{3} / \mathrm{CH}_{3} \mathrm{NH}_{3} \mathrm{PbI}_{3-X} \mathrm{Cl}_{X}$ Perovskite Solar Cells: Kinetics and Mechanisms. Adv. Energy Mater. 2016, 6 (13), 1600014.

(22) Pont, S.; Bryant, D.; Lin, C.-T.; Aristidou, N.; Wheeler, S.; Ma, X.; Godin, R.; Haque, S. A.; Durrant, J. R. Tuning $\mathrm{CH}_{3} \mathrm{NH}_{3} \mathrm{~Pb}$ $\left(\mathrm{I}_{1-x} \mathrm{Br}_{x}\right)_{3}$ Perovskite Oxygen Stability in Thin Films and Solar Cells. J. Mater. Chem. A 2017, 5 (20), 9553-9560.

(23) Zhang, L.; Sit, P. H.-L. Ab Initio Study of the Role of Oxygen and Excess Electrons in the Degradation of $\mathrm{CH}_{3} \mathrm{NH}_{3} \mathrm{PbI}_{3}$. J. Mater. Chem. A 2017, 5 (19), 9042-9049.

(24) Sun, Q.; Fassl, P.; Becker-Koch, D.; Bausch, A.; Rivkin, B.; Bai, S.; Hopkinson, P. E.; Snaith, H. J.; Vaynzof, Y. Role of Microstructure in Oxygen Induced Photodegradation of Methylammonium Lead Triiodide Perovskite Films. Adv. Energy Mater. 2017, 7 (20), 1700977.

(25) Aristidou, N.; Eames, C.; Sanchez-Molina, I.; Bu, X.; Kosco, J.; Islam, M. S.; Haque, S. A. Fast Oxygen Diffusion and Iodide Defects Mediate Oxygen-Induced Degradation of Perovskite Solar Cells. Nat. Commun. 2017, 8, 15218.

(26) Aristidou, N.; Eames, C.; Islam, M. S.; Haque, S. A. Insights into the Increased Degradation Rate of $\mathrm{CH}_{3} \mathrm{NH}_{3} \mathrm{PbI}_{3}$ Solar Cells in Combined Water and $\mathrm{O}_{2}$ Environments. J. Mater. Chem. A 2017, 5 (48), 25469-25475.

(27) Niu, G.; Li, W.; Meng, F.; Wang, L.; Dong, H.; Qiu, Y. Study on the Stability of $\mathrm{CH}_{3} \mathrm{NH}_{3} \mathrm{PbI}_{3}$ Films and the Effect of PostModification by Aluminum Oxide in All-Solid-State Hybrid Solar Cells. J. Mater. Chem. A 2014, 2 (3), 705-710.

(28) Leguy, A. M. A.; Hu, Y.; Campoy-Quiles, M.; Alonso, M. I.; Weber, O. J.; Azarhoosh, P.; van Schilfgaarde, M.; Weller, M. T.; Bein, T.; Nelson, J.; et al. Reversible Hydration of $\mathrm{CH}_{3} \mathrm{NH}_{3} \mathrm{PbI}_{3}$ in Films,
Single Crystals, and Solar Cells. Chem. Mater. 2015, 27 (9), 33973407.

(29) Christians, J. A.; Miranda Herrera, P. A.; Kamat, P. V. Transformation of the Excited State and Photovoltaic Efficiency of $\mathrm{CH}_{3} \mathrm{NH}_{3} \mathrm{PbI}_{3}$ Perovskite upon Controlled Exposure to Humidified Air. J. Am. Chem. Soc. 2015, 137 (4), 1530-1538.

(30) Yang, J.; Siempelkamp, B. D.; Liu, D.; Kelly, T. L. Investigation of $\mathrm{CH}_{3} \mathrm{NH}_{3} \mathrm{PbI}_{3}$ Degradation Rates and Mechanisms in Controlled Humidity Environments Using in Situ Techniques. ACS Nano 2015, 9 (2), 1955-1963.

(31) Shirayama, M.; Kato, M.; Miyadera, T.; Sugita, T.; Fujiseki, T.; Hara, S.; Kadowaki, H.; Murata, D.; Chikamatsu, M.; Fujiwara, H. Degradation Mechanism of $\mathrm{CH}_{3} \mathrm{NH}_{3} \mathrm{PbI}_{3}$ Perovskite Materials upon Exposure to Humid Air. J. Appl. Phys. 2016, 119 (11), 115501.

(32) Lin, W. C.; Chang, H. Y.; Abbasi, K.; Shyue, J. J.; Burda, C. 3D In Situ ToF-SIMS Imaging of Perovskite Films under Controlled Humidity Environmental Conditions. Adv. Mater. Interfaces 2017, 4 (2), 1600673.

(33) Salado, M.; Contreras-Bernal, L.; Calio, L.; Todinova, A.; Lopez-santos, C.; Ahmad, S.; Borras, A.; Idígoras, J. A.; Anta, J. A. Impact of Moisture on Efficiency-Determining Electronic Processes in Perovskite Solar Cells. J. Mater. Chem. A 2017, 5 (22), 10917-10927.

(34) Nagabhushana, G. P.; Shivaramaiah, R.; Navrotsky, A. Direct Calorimetric Verification of Thermodynamic Instability of Lead Halide Hybrid Perovskites. Proc. Natl. Acad. Sci. U. S. A. 2016, 113 (28), 7717-7721.

(35) Ivanov, I. L.; Steparuk, A. S.; Bolyachkina, M. S.; Tsvetkov, D. S.; Safronov, A. P.; Zuev, A. Y. Thermodynamics of Formation of Hybrid Perovskite-Type Methylammonium Lead Halides. J. Chem. Thermodyn. 2018, 116, 253-258.

(36) Latini, A.; Gigli, G.; Ciccioli, A. A Study on the Nature of the Thermal Decomposition of Methylammonium Lead Iodide Perovskite, $\mathrm{CH}_{3} \mathrm{NH}_{3} \mathrm{PbI}_{3}:$ An Attempt to Rationalise Contradictory Experimental Results. Sustain. Energy Fuels 2017, 1 (6), 1351-1357.

(37) Ciccioli, A.; Latini, A. Thermodynamics and the Intrinsic Stability of Lead Halide Perovskites $\mathrm{CH}_{3} \mathrm{NH}_{3} \mathrm{PbX}_{3}$. J. Phys. Chem. Lett. 2018, 9 (13), 3756-3765.

(38) Onoda-Yamamuro, N.; Matsuo, T.; Suga, H. Calorimetric and IR Spectroscopic Studies of Phase Transitions in Methylammonium Trihalogenoplumbates (II). J. Phys. Chem. Solids 1990, 51 (12), $1383-1395$.

(39) Stoumpos, C. C.; Malliakas, C. D.; Kanatzidis, M. G. Semiconducting Tin and Lead Iodide Perovskites with Organic Cations: Phase Transitions, High Mobilities, and Near-Infrared Photoluminescent Properties. Inorg. Chem. 2013, 52 (15), 90199038.

(40) Prochowicz, D.; Franckevičius, M.; Cieślak, A. M.; Zakeeruddin, S. M.; Grätzel, M.; Lewiński, J. Mechanosynthesis of the Hybrid Perovskite $\mathrm{CH}_{3} \mathrm{NH}_{3} \mathrm{PbI}_{3}$ : Characterization and the Corresponding Solar Cell Efficiency. J. Mater. Chem. A 2015, 3 (41), 20772-20777.

(41) Manukyan, K. V.; Yeghishyan, A. V.; Moskovskikh, D. O.; Kapaldo, J.; Mintairov, A.; Mukasyan, A. S. Mechanochemical Synthesis of Methylammonium Lead Iodide Perovskite. J. Mater. Sci. 2016, 51 (19), 9123-9130.

(42) Lee, M. M.; Teuscher, J.; Miyasaka, T.; Murakami, T. N.; Snaith, H. J. Efficient Hybrid Solar Cells Based on Meso-Superstructured Organometal Halide Perovskites. Science (Washington, DC, U. S.) 2012, 338 (6107), 643-647.

(43) Kim, H.-S.; Lee, C.-R.; Im, J.-H.; Lee, K.-B.; Moehl, T.; Marchioro, A.; Moon, S.-J.; Humphry-Baker, R.; Yum, J.-H.; Moser, J. E.; et al. Lead Iodide Perovskite Sensitized All-Solid-State Submicron Thin Film Mesoscopic Solar Cell with Efficiency Exceeding 9\%. Sci. Rep. 2012, 2 (1), 591.

(44) Yang, S.; Zheng, Y. C.; Hou, Y.; Chen, X.; Chen, Y.; Wang, Y.; Zhao, H.; Yang, H. G. Formation Mechanism of Freestanding $\mathrm{CH}_{3} \mathrm{NH}_{3} \mathrm{PbI}_{3}$ Functional Crystals: In Situ Transformation vs Dissolution-Crystallization. Chem. Mater. 2014, 26 (23), 67056710. 
(45) Jeon, N. J.; Noh, J. H.; Kim, Y. C.; Yang, W. S.; Ryu, S.; Seok, S. Il. Solvent Engineering for High-Performance Inorganic-Organic Hybrid Perovskite Solar Cells. Nat. Mater. 2014, 13 (9), 897-903.

(46) Ahn, N.; Son, D. Y.; Jang, I. H.; Kang, S. M.; Choi, M.; Park, N. G. Highly Reproducible Perovskite Solar Cells with Average Efficiency of $18.3 \%$ and Best Efficiency of $19.7 \%$ Fabricated via Lewis Base Adduct of Lead(II) Iodide. J. Am. Chem. Soc. 2015, 137 (27), 8696-8699.

(47) Guo, Y.; Shoyama, K.; Sato, W.; Matsuo, Y.; Inoue, K.; Harano, K.; Liu, C.; Tanaka, H.; Nakamura, E. Chemical Pathways Connecting Lead(II) Iodide and Perovskite via Polymeric Plumbate(II) Fiber. J. Am. Chem. Soc. 2015, 137 (50), 15907-15914.

(48) Barrit, D.; Cheng, P.; Tang, M.-C.; Wang, K.; Dang, H.; Smilgies, D.-M.; Liu, S. F.; Anthopoulos, T. D.; Zhao, K.; Amassian, A. Impact of the Solvation State of Lead Iodide on Its Two-Step Conversion to $\mathrm{MAPbI}_{3}$ : An In Situ Investigation. Adv. Funct. Mater. 2019, 1807544, 1807544.

(49) Juarez-Perez, E. J.; Hawash, Z.; Raga, S. R.; Ono, L. K.; Qi, Y. Thermal Degradation of $\mathrm{CH}_{3} \mathrm{NH}_{3} \mathrm{PbI}_{3}$ Perovskite into $\mathrm{NH}_{3}$ and $\mathrm{CH}_{3} \mathrm{I}$ Gases Observed by Coupled Thermogravimetry-mass Spectrometry Analysis. Energy Environ. Sci. 2016, 9 (11), 3406-3410.

(50) Deretzis, I.; Smecca, E.; Mannino, G.; La Magna, A.; Miyasaka, T.; Alberti, A. Stability and Degradation in Hybrid Perovskites: Is the Glass Half-Empty or Half-Full? J. Phys. Chem. Lett. 2018, 9, 30003007.

(51) $\mathrm{p} K_{\mathrm{b}}$ value for Methylamine and Formamidine. CAS-SciFinder.

(52) Zhang, T.; Meng, X.; Bai, Y.; Xiao, S.; Hu, C.; Yang, Y.; Chen, H.; Yang, S.; et al. Profiling the Organic Cation-Dependent Degradation of Organolead Halide Perovskite Solar Cells. J. Mater. Chem. A 2017, 5 (3), 1103-1111.

(53) Huang, R. J.; Seitz, K.; Neary, T.; O’Dowd, C. D.; Platt, U.; Hoffmann, T. Observations of High Concentrations of $\mathrm{I}_{2}$ and IO in Coastal Air Supporting Iodine-Oxide Driven Coastal New Particle Formation. Geophys. Res. Lett. 2010, 37 (3), 1-5.

(54) Saiz-Lopez, A.; Plane, J. M. C.; Baker, A. R.; Carpenter, L. J.; Von Glasow, R.; Gómez Martín, J. C.; McFiggans, G.; Saunders, R. W. Atmospheric Chemistry of Iodine. Chem. Rev. 2012, 112 (3), 17731804.

(55) Senocrate, A.; Acartürk, T.; Kim, G. Y.; Merkle, R.; Starke, U.; Grätzel, M.; Maier, J. Interaction of Oxygen with Halide Perovskites. J. Mater. Chem. A 2018, 6 (23), 10847-10855.

(56) Yang, T.; Jeon, N. J.; Shin, H.; Shin, S. S.; Kim, Y. Y.; Seo, J. Achieving Long-Term Operational Stability of Perovskite Solar Cells with a Stabilized Efficiency Exceeding 20\% after $1000 \mathrm{H}$. Adv. Sci. 2019, 1900528, 1900528.

(57) Boyd, C. C.; Cheacharoen, R.; Leijtens, T.; McGehee, M. D. Understanding Degradation Mechanisms and Improving Stability of Perovskite Photovoltaics. Chem. Rev. 2019, 119 (5), 3418-3451.

(58) Wang, R.; Mujahid, M.; Duan, Y.; Wang, Z.-K.; Xue, J.; Yang, Y. A Review of Perovskites Solar Cell Stability. Adv. Funct. Mater. 2019, 1808843.

(59) Müller, C.; Glaser, T.; Plogmeyer, M.; Sendner, M.; Döring, S.; Bakulin, A. A.; Brzuska, C.; Scheer, R.; Pshenichnikov, M. S.; Kowalsky, W.; et al. Water Infiltration in Methylammonium Lead Iodide Perovskite: Fast and Inconspicuous. Chem. Mater. 2015, 27 (22), 7835-7841.

(60) Zhao, J.; Cai, B.; Luo, Z.; Dong, Y.; Zhang, Y.; Xu, H.; Hong, B.; Yang, Y.; Li, L.; Zhang, W.; et al. Investigation of the Hydrolysis of Perovskite Organometallic Halide $\mathrm{CH}_{3} \mathrm{NH}_{3} \mathrm{PbI}_{3}$ in Humidity Environment. Sci. Rep. 2016, 6, 21976.

(61) Huang, J.; Tan, S.; Lund, P. D.; Zhou, H. Impact of $\mathrm{H}_{2} \mathrm{O}$ on Organic-inorganic Hybrid Perovskite Solar Cells. Energy Environ. Sci. 2017, 10 (11), 2284-2311.

(62) Senocrate, A.; Maier, J. Solid-State Ionics of Hybrid Halide Perovskites. J. Am. Chem. Soc. 2019, 141 (21), 8382-8396.

(63) Kim, G. Y.; Senocrate, A.; Yang, T.-Y.; Gregori, G.; Grätzel, M.; Maier, J. Large Tunable Photoeffect on Ion Conduction in Halide Perovskites and Implications for Photodecomposition. Nat. Mater. 2018, 17 (5), 445-449.
(64) Snaith, H. J.; Pathak, S.; Lee, M. M.; Leijtens, T.; Abate, A.; Eperon, G. E. Overcoming Ultraviolet Light Instability of Sensitized $\mathrm{TiO}_{2}$ with Meso-Superstructured Organometal Tri-Halide Perovskite Solar Cells. Nat. Commun. 2013, 4 (1), 1-8.

(65) Berhe, T. A.; Su, W.-N.; Chen, C.-H.; Pan, C.-J.; Cheng, J.-H.; Chen, H.-M.; Tsai, M.-C.; Chen, L.-Y.; Dubale, A. A.; Hwang, B.-J. Organometal Halide Perovskite Solar Cells: Degradation and Stability. Energy Environ. Sci. 2016, 9 (2), 323-356.

(66) Dawson, J. A.; Naylor, A. J.; Eames, C.; Roberts, M.; Zhang, W.; Snaith, H. J.; Bruce, P. G.; Islam, M. S. Mechanisms of Lithium Intercalation and Conversion Processes in Organic-Inorganic Halide Perovskites. ACS Energy Lett. 2017, 2 (8), 1818-1824.

(67) Cacovich, S.; Ciná, L.; Matteocci, F.; Divitini, G.; Midgley, P. A.; Di Carlo, A.; Ducati, C. Gold and Iodine Diffusion in Large Area Perovskite Solar Cells under Illumination. Nanoscale 2017, 9 (14), $4700-4706$.

(68) Gunasekaran, R. K.; Chinnadurai, D.; Selvaraj, A. R.; Rajendiran, R.; Senthil, K.; Prabakar, K. Revealing the SelfDegradation Mechanisms in Methylammonium Lead Iodide Perovskites in Dark and Vacuum. ChemPhysChem 2018, 19, 1507-1513.

(69) Zhao, Y.; Zhou, W.; Tan, H.; Fu, R.; Li, Q.; Lin, F.; Yu, D.; Walters, G.; Sargent, E. H.; Zhao, Q. Mobile-Ion-Induced Degradation of Organic Hole-Selective Layers in Perovskite Solar Cells. J. Phys. Chem. C 2017, 121 (27), 14517-14523.

(70) Besleaga, C.; Abramiuc, L. E.; Stancu, V.; Tomulescu, A. G.; Sima, M.; Trinca, L.; Plugaru, N.; Pintilie, L.; Nemnes, G. A.; Iliescu, M.; et al. Iodine Migration and Degradation of Perovskite Solar Cells Enhanced by Metallic Electrodes. J. Phys. Chem. Lett. 2016, 7 (24), $5168-5175$.

(71) Wang, D.; Wright, M.; Elumalai, N. K.; Uddin, A. Stability of Perovskite Solar Cells. Sol. Energy Mater. Sol. Cells 2016, 147, 255275.

(72) Bakr, Z. H.; Wali, Q.; Fakharuddin, A.; Schmidt-Mende, L.; Brown, T. M.; Jose, R. Advances in Hole Transport Materials Engineering for Stable and Efficient Perovskite Solar Cells. Nano Energy 2017, 34, 271-305.

(73) Rakstys, K.; Igci, C.; Nazeeruddin, M. K. Efficiency vs. Stability: Dopant-Free Hole Transporting Materials towards Stabilized Perovskite Solar Cells. Chem. Sci. 2019, 10 (28), 6748-6769.

(74) Maier, J. Physical Chemistry of Ionic Materials; John Wiley \& Sons, Ltd: Chichester, U.K., 2004.

(75) Mizusaki, J.; Arai, K.; Fueki, K. Ionic Conduction of the Perovskite-Type Halides. Solid State Ionics 1983, 11 (3), 203-211.

(76) Yamada, K. Chloride Ion Conductor $\mathrm{CH}_{3} \mathrm{NH}_{3} \mathrm{GeCl}_{3}$ Studied by Rietveld Analysis of X-Ray Diffraction and ${ }^{35} \mathrm{Cl}$ NMR. Solid State Ionics 1995, 79, 152-157.

(77) Yang, T.-Y.; Gregori, G.; Pellet, N.; Grätzel, M.; Maier, J. The Significance of Ion Conduction in a Hybrid Organic-Inorganic LeadIodide-Based Perovskite Photosensitizer. Angew. Chem., Int. Ed. 2015, 54 (27), 7905-7910.

(78) Senocrate, A.; Moudrakovski, I.; Kim, G. Y.; Yang, T.-Y.; Gregori, G.; Grätzel, M.; Maier, J. The Nature of Ion Conduction in Methylammonium Lead Iodide: A Multimethod Approach. Angew. Chem., Int. Ed. 2017, 56 (27), 7755-7759.

(79) Senocrate, A.; Moudrakovski, I.; Acartürk, T.; Merkle, R.; Kim, G. Y.; Starke, U.; Grätzel, M.; Maier, J. Slow $\mathrm{CH}_{3} \mathrm{NH}_{3}{ }^{+}$Diffusion in $\mathrm{CH}_{3} \mathrm{NH}_{3} \mathrm{PbI}_{3}$ under Light Measured by Solid-State NMR and Tracer Diffusion. J. Phys. Chem. C 2018, 122 (38), 21803-21806.

(80) Pellet, N.; Teuscher, J.; Maier, J.; Grätzel, M. Transforming Hybrid Organic Inorganic Perovskites by Rapid Halide Exchange. Chem. Mater. 2015, 27 (6), 2181-2188.

(81) Eperon, G. E.; Beck, C. E.; Snaith, H. J. Cation Exchange for Thin Film Lead Iodide Perovskite Interconversion. Mater. Horiz. 2016, 3 (1), 63-71.

(82) Tian, Y.; Peter, M.; Unger, E.; Abdellah, M. A.; Zheng, K.; Pullerits, T.; Yartsev, A. P.; Sundström, V.; Scheblykin, I. G. Mechanistic Insights into Perovskite Photoluminescence Enhancement: Light Curing with Oxygen Can Boost Yield Thousandfold. Phys. Chem. Chem. Phys. 2015, 17 (38), 24978-24987. 
(83) Senocrate, A.; Yang, T.-Y.; Gregori, G.; Kim, G. Y.; Grätzel, M.; Maier, J. Charge Carrier Chemistry in Methylammonium Lead Iodide. Solid State Ionics 2018, 321, 69-74.

(84) Saliba, M.; Matsui, T.; Domanski, K.; Seo, J.-Y.; Ummadisingu, A.; Zakeeruddin, S. M.; Correa-Baena, J.-P.; Tress, W. R.; Abate, A.; Hagfeldt, A.; et al. Incorporation of Rubidium Cations into Perovskite Solar Cells Improves Photovoltaic Performance. Science (Washington, DC, U. S.) 2016, 354 (6309), 206-209.

(85) Kubicki, D. J.; Prochowicz, D.; Hofstetter, A.; Zakeeruddin, S. M.; Grätzel, M.; Emsley, L. Phase Segregation in Cs-, Rb- and KDoped Mixed-Cation $(\mathrm{MA})_{x}(\mathrm{FA})_{1-X} \mathrm{PbI}_{3}$ Hybrid Perovskites from Solid-State NMR. J. Am. Chem. Soc. 2017, 139 (40), 14173-14180.

(86) Hoke, E. T.; Slotcavage, D. J.; Dohner, E. R.; Bowring, A. R.; Karunadasa, H. I.; McGehee, M. D. Reversible Photo-Induced Trap Formation in Mixed-Halide Hybrid Perovskites for Photovoltaics. Chem. Sci. 2015, 6 (1), 613-617.

(87) Brivio, F.; Caetano, C.; Walsh, A. Thermodynamic Origin of Photoinstability in the $\mathrm{CH}_{3} \mathrm{NH}_{3} \mathrm{~Pb}\left(\mathrm{I}_{1-X} \mathrm{Br}_{x}\right)_{3}$ Hybrid Halide Perovskite Alloy. J. Phys. Chem. Lett. 2016, 7 (6), 1083-1087.

(88) Kim, G. Y.; Senocrate, A.; Maier, J. Photo-Effect on Ion Conduction in Mixed Cation and Mixed Anion Perovskites. In Preparation.

(89) Grancini, G.; Nazeeruddin, M. K. Dimensional Tailoring of Hybrid Perovskites for Photovoltaics. Nat. Rev. Mater. 2019, 4 (1), 422.

(90) Juarez-Perez, E. J.; Ono, L. K.; Maeda, M.; Jiang, Y.; Hawash, Z.; Qi, Y. Photodecomposition and Thermal Decomposition in Methylammonium Halide Lead Perovskites and Inferred Design Principles to Increase Photovoltaic Device Stability. J. Mater. Chem. A 2018, 6 (20), 9604-9612. 